Cite this: Chem. Commun., 2014, 50, 5233

Received 2nd October 2013, Accepted 29th November 2013

DOI: $10.1039 / c 3 c c 47552 b$

www.rsc.org/chemcomm

\section{Charge-modulated self-assembly and growth of conjugated polyelectrolyte-polyoxometalate hybrid networks $\dagger$}

\author{
Judith E. Houston, ${ }^{a}$ Adam R. Patterson, ${ }^{a}$ Anil C. Jayasundera, ${ }^{a}$ Wolfgang Schmitt ${ }^{a b}$ \\ and Rachel C. Evans*ab
}

\begin{abstract}
Self-assembly of an anionic polyoxometalate with cationic conjugated polyelectrolytes leads to hybrid supramolecular networks whose dimensionality is controlled by the chain length and steric charge distribution.
\end{abstract}

Conjugated polyelectrolytes (CPEs) have attracted significant interest due to their potential applications in optical sensing and imaging, light-emitting diodes and photovoltaic devices. ${ }^{1}$ They comprise of an extended $\pi$-conjugated backbone decorated with side-chains containing ionic terminal groups, thus coupling the optoelectronic properties of organic semiconductors and the charge-mediated behaviour typical of polyelectrolytes. Since the optoelectronic properties of CPEs are intrinsically linked to the conformation of the polymer backbone, ${ }^{2}$ understanding and obtaining control of the CPE conformation is a key requirement for the development of efficient organic electronic devices.

Self-assembly is an elegant method for the fabrication of conjugated polymer (CP) nanostructures. ${ }^{3}$ CPEs are inherently amphiphilic, which facilitates their self-assembly into ordered aggregates with diverse morphologies in different solvents. ${ }^{4}$ They may also undergo electrostatic co-assembly with oppositely charged species (e.g. metal ions $^{5 a}$ and complexes, ${ }^{5 b} \mathrm{DNA}^{5 c, d}$ surfactants $^{5 e, f}$ ) to construct complex supramolecular structures. Recently, cooperative physical interactions have been shown to play an influential role in determining the phase miscibility, ${ }^{6 a-c}$ morphology ${ }^{6 c, d}$ and orientation $^{6 e-g}$ of the individual components in CP organicinorganic hybrid materials. The challenge, however, is to identify physicochemically compatible organic and inorganic building blocks, which both resist phase separation and introduce the possibility of synergistic functionality to the material.

Polyoxometalates (POMs) are anionic metal-oxide clusters that are frequently used as components to construct functionalised

\footnotetext{
${ }^{a}$ School of Chemistry, The University of Dublin, Trinity College, Dublin 2, Ireland. E-mail: raevans@tcd.ie; Tel: +35318964215

${ }^{b}$ Centre for Research on Adaptive Nanostructures and Nanodevices (CRANN), Trinity College Dublin, Dublin 2, Ireland

$\dagger$ Electronic supplementary information (ESI) available: Synthesis of POM, instrumental methods, DLS, FTIR, NMR, TGA, SEM and AFM data. See DOI: $10.1039 / \mathrm{c} 3 \mathrm{cc} 47552 \mathrm{~b}$
}

organic-inorganic hybrid materials, both via covalent linkages ${ }^{7}$ and ionic self-assembly. ${ }^{8}$ POMs exhibit rich redox and photoactivity and are well-known to undergo potential- or light-induced electron and proton transfer processes. ${ }^{9}$ Moreover, self-assembly has often been proposed as a viable strategy for the incorporation of POMs into nanodevices with tailored morphology. ${ }^{10}$ It is therefore somewhat surprising that $\mathrm{CP} / \mathrm{CPE}-\mathbf{P O M}$ hybrid systems have been largely overlooked. Poly(phenylene) $\mathrm{s}^{11 a, b}$ and poly(thiophenes) ${ }^{11 c}$ containing the covalently-grafted hexamolybdate $\left[\mathrm{Mo}_{6} \mathrm{O}_{18}\right]^{2-}$ have been reported to undergo solvent-induced self-assembly into vesicles in solution. POM-CP hybrids prepared by in situ electropolymerisation have also been described. ${ }^{12}$ Herein, we demonstrate how electrostatic interactions between an anionic lacunary decatungstosilicate $\mathrm{K}_{8}\left[\mathrm{SiW}_{10} \mathrm{O}_{36}\right](\mathbf{P O M})^{13}$ and cationic CPEs in water result in their co-assembly into hybrid networks, that can subsequently be transferred to thin films. We show that the direction of self-assembly and thus, the dimensionality of the resulting supramolecular networks is controlled by the steric distribution of the charged side-chains on the CPE. To the best of our knowledge this is the first report of a self-assembled CPE-POM organicinorganic hybrid exhibiting transferrable supramolecular organisation from solution to the solid-state.

Two cationic CPEs, differing significantly in their chain length, number of repeat units (r.u.) and distribution of side chains were chosen: (i) poly[(2,5-bis(2-( $N, N$-diethylammoniumbromide)ethoxy)1,4-phenylene)-alt-1,4-phenylene] (NET, $M_{\mathrm{w}} \approx 1054 \mathrm{~g} \mathrm{~mol}^{-1}$ ) and (ii) $\operatorname{poly}\left[\left(9,9-\mathrm{di}\left(3,3^{\prime}-N, N^{\prime}\right.\right.\right.$-trimethylammonium)propylfluorenyl-2,7diyl)-alt-(1,4-phenylene)] (PFP, $M_{\mathrm{w}} \approx 10000-15000 \mathrm{~g} \mathrm{~mol}^{-1}$ ) (Fig. 1). While NET is marketed as a polymer, it is in fact an oligomer, containing on average just 2 r.u. per chain; in contrast PFP has 14-22 r.u. per chain. Both CPEs contain two ammonium groups per r.u.; however, since the side-chains are located at adjacent and opposite positions in PFP and NET, respectively, the steric charge distribution differs substantially.

Electrostatic association between cationic CPEs and the anionic POM in solution is expected to affect the optical properties. On addition of POM to aqueous solutions of NET and PFP, three distinct spectral changes are observed in the UV/Vis 
(a)

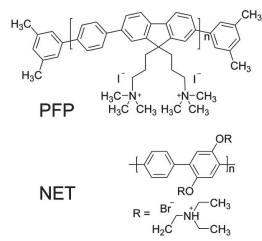

(c) $\mathrm{POM} / \mathrm{NET}=1$

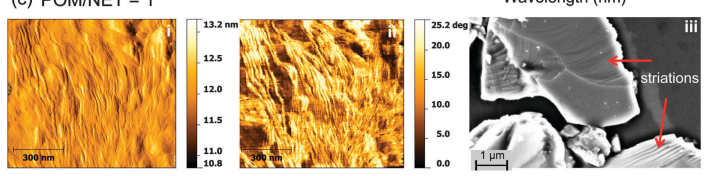

(d) $\mathrm{POM} / \mathrm{PFP}=0.5$

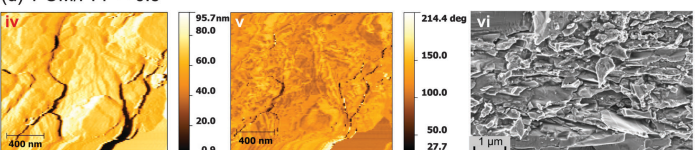

Fig. 1 (a) Chemical structures of CPEs, (b) LD spectra for NET and POM/ NET $=1\left([\mathrm{NET}]=5.48 \times 10^{-5} \mathrm{M}(\right.$ r.u) $)$. (c) and (d) show the topography of $\mathrm{POM} / \mathrm{NET}=1$ and POM/PFP $=0.5$ films obtained from amplitude (i, iv) and phase (ii, v) AFM images and SEM (iii, vi).
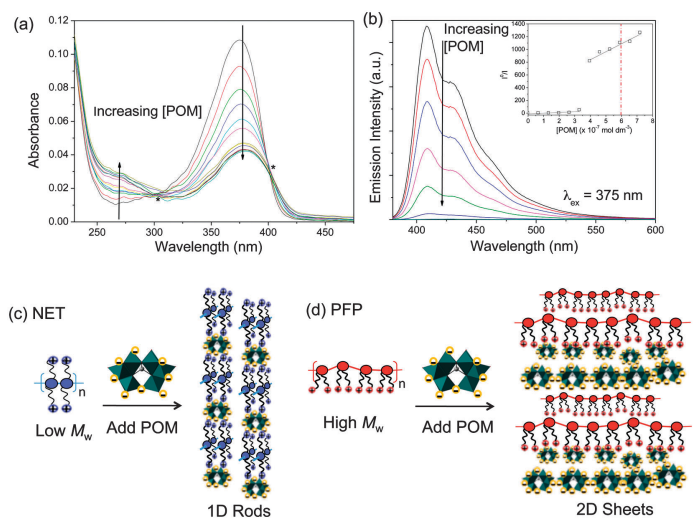

Fig. 2 (a) UV/Vis absorption and (b) PL spectra of PFP in water $\left(2.4 \times 10^{-6} \mathrm{M}\right.$ (r.u.)) on addition of POM $\left(0-7.2 \times 10^{-7} \mathrm{M}\right)$. Inset: Stern Volmer plot (red dashed line indicates POM/CPE $=1$ ). *Isosbestic point $(c)$ and $(d)$ schematic representation of the proposed mechanism of self-assembly of NET-POM and PFP-POM into hybrid networks

absorption spectrum, shown in Fig. 2 for PFP: (1) an increase in the absorbance at $250 \mathrm{~nm}$ (assigned to the POM O $\rightarrow$ W charge transfer band). (2) A decrease and red-shift in the absorption maximum of the CPE $\left(\Delta \lambda_{\max }=331-344 \mathrm{~nm}\right.$ and $\Delta \lambda_{\max }=375-380 \mathrm{~nm}$ for NET and PFP, respectively), which is accompanied by red-edge band broadening. This is indicative of an increase in the effective conjugation length of the CPE. ${ }^{5 c-f, 14}$ (3) The emergence of isosbestic points, at $\sim 303 \mathrm{~nm}$ for both CPEs, and $342 \mathrm{~nm}$ (NET) and $402 \mathrm{~nm}$ (PFP), provides the first clear indication for CPE-POM association. These trends plateau at charge neutralisation $(\mathbf{P O M} / \mathrm{CPE}=1){ }^{15}$ demonstrating that electrostatic interactions play a major role in the binding affinity (Fig. S4, ESI $\dagger$ ). The CPE photoluminescence (PL) is quenched upon addition of POM to the solution, as observed previously for cationic $\mathrm{Ru}(\mathrm{II})$ polypyridyl complexes and metallopolymers upon electrostatic association with POMs. ${ }^{9 c, d}$ Both PFP and NET exhibit linear Stern-Volmer plots for POM/CPE ratios below charge neutralisation, yielding Stern-Volmer constants whose values are indicative of static quenching $\left(K_{\mathrm{SV}}=5.73( \pm 1.54) \times 10^{6} \mathrm{M}^{-1}\right.$ and $K_{\mathrm{SV}}=1.16( \pm 0.52) \times 10^{8} \mathrm{M}^{-1}$ for NET and PFP, respectively). CPs are known to exhibit amplified fluorescence quenching due to efficient exciton migration along the conjugated backbone. ${ }^{1,5 a}$ Increased quenching of the PFP emission is thus consistent with its higher $M_{\mathrm{W}}$ when compared with NET. As the POM/CPE charge ratio increases, the Stern-Volmer plots exhibit sigmoidal character, with the transition occurring at a critical charge ratio of 0.67 for PFP and 1.12 for NET. This is indicative of increased amplification of the PL quenching as the CPE chains are brought into closer proximity through association with the POM. ${ }^{5 a, d}$

The hydrodynamic radius of the POM/CPE aggregates in water was evaluated using dynamic light scattering (DLS). The $z$-average radii $\left(r_{\mathrm{h}}\right)$ of the individual components are $115( \pm 9) \mathrm{nm}$ for POM, $123( \pm 36) \mathrm{nm}$ for NET and $201( \pm 23) \mathrm{nm}$ for PFP. Addition of increasing POM to a CPE solution results in a bimodal distribution, indicating the presence of both free CPE and POM/ CPE aggregates. For both systems, $r_{\mathrm{h}}$ remains constant until a critical POM/CPE charge ratio is attained; at this point the global $r_{\mathrm{h}}$ increases to $163( \pm 23) \mathrm{nm}(\mathbf{P O M} / \mathrm{CPE}=1)$ and $227( \pm 23) \mathrm{nm}$ $(\mathbf{P O M} / \mathrm{CPE}=0.8)$ for NET and PFP, respectively (Fig. S5, ESI $\dagger$ ). Addition of further POM results in the formation of larger aggregates $\left(r_{\mathrm{h}} \sim 500-600 \mathrm{~nm}\right)$; however, no visible signs of turbidity or precipitation are observed.

The mode of binding was examined by ${ }^{1} \mathrm{H}$ NMR, infrared (FTIR) and linear dichroism (LD) spectroscopy. For POM/NET, increased sharpness in the NMR signal at $9.6 \mathrm{ppm}$, accompanied by a $10 \mathrm{~cm}^{-1}$ shift in the $\nu_{\mathrm{N}-\mathrm{H}}$ stretching mode $\left(\sim 3384 \mathrm{~cm}^{-1}\right)$ upon POM addition provide evidence for direct electrostatic interaction between the N-H group on NET and the POM (Fig. S6 and S7 ESI $\dagger$ ). In the absence of POM, no LD signal is observed, indicating that the polymer chains are isotropically distributed (Fig. 1b). However, for POM/NET = 1, three broad signals are resolved: (1) a negative band centred at $\sim 260 \mathrm{~nm}$ (POM); (2) two positive bands at $350 \mathrm{~nm}$ and $443 \mathrm{~nm}$ (CPE). The net LD signal indicates that both the POM and CPE have aligned upon co-assembly. Moreover, the sign and magnitude of the individual absorption bands provide an indication of the relative orientation. Since the transition moment of CPs usually lies parallel to the backbone, ${ }^{16}$ the positive LD signal indicates the CPE chains must be aligned parallel to the local orientation axis. The negative LD signal at $260 \mathrm{~nm}$ infers that bound POM clusters lie perpendicular to aligned CPE chains. A comparable trend was observed for PFP, with the exception that the sign of the bands were reversed, thus indicating a higher density of POM clusters aligned parallel to the local orientation axis (Fig. S9, ESI $\dagger$ ).

Atomic force microscopy (AFM) and scanning electron microscopy (SEM) were used to determine if hybrid networks formed in solution could be transferred as thin films with the retention of their nanoscale organisation, which is critical for potential device applications (Fig. 1c and d). Individually, РОМ ( 100-300 nm), NET ( 200-300 nm) and PFP ( 200-300 nm) all form amorphous aggregates (Fig. S10, ESI $\dagger$ ). Upon mixing, POM and NET retain their amorphous character until charge balance is reached; at this point 1D strand-like structures ( 20-35 $\mathrm{nm}$ in diameter) become apparent on the film surface. 
In contrast, structural features emerge at a charge ratio of $\mathbf{P O M} / \mathbf{P F P}=0.5$, with the observation of stacked, extended plate-like structures, whose thickness varies between 40-200 nm. Above charge balance, much larger (700-1500 nm) amorphous aggregates are observed, which become dispersed in a charge excess of POM (Fig. S12 and S13 ESI $\dagger$ ).

The global results indicate distinct self-assembly patterns for NET-POM and PFP-POM in solution. The onset of selfassembly occurs at lower POM/CPE charge ratios for PFP than NET ( 0.5-0.8 and 1, respectively). The amplified PL quenching observed around and above charge balance suggests increased interchain interactions for PFP, which is consistent with observed formation of larger aggregates for this system. LD results suggest the formation of $1 \mathrm{D}$ chain-like aggregates for NET-POM, with the POM orientated perpendicular to the conjugated backbone. These individual fibres assemble in the drop cast films into lamellar packing arrangements with defined hydrophilic inorganic and hydrophobic organic areas (AFM). In contrast, PFP-POM forms extended 2D plate-like arrays in solution, which are transferred to the solid-state (AFM, SEM). Based on these observations, the chain length and steric charge distribution on the CPEs, and the size and charge density/distribution of the less-symmetrical, dilacunary POM unit that structurally relates to the $\gamma$-Keggin isomer, ${ }^{13}$ we propose two distinct mechanisms for self-assembly (Fig. 2). For NET, the ionic chains are distributed on opposite sides of each r.u., promoting the formation of $1 \mathrm{D}$-chains of alternating POM and NET. The CPE chain length $(\sim 1.4 \mathrm{~nm})$ matches the diameter of the POM $(\sim 1.0 \mathrm{~nm})$, which inhibits extended growth in 2D. In contrast, PFP presents two adjacent ionic chains per r.u. available for Coulombic interaction with the POM. Since the PFP chains are significantly longer (16.0-25.1 nm) than the POM diameter, this facilitates co-assembly with multiple POM units across the chain length resulting in 2D layers. Simultaneously, hydrophobic and van der Waals interactions drive the stacking of these layers.

In summary, we have demonstrated the targeted formation of CPE-POM supramolecular networks via electrostatic association. While we have focused here on the representative POM $\mathrm{K}_{8}\left[\mathrm{SiW}_{10} \mathrm{O}_{36}\right]$ and NET and PFP as the CPEs, our approach is expected to be general and extendable to other CPE-POM hybrid systems. Importantly, we have shown that the selfassembly process is influenced by the chain length and steric charge distribution on the CPE, which facilitates tuning of the dimensionality of the supramolecular structures formed. Given the breadth of molecular topologies, surface charge densities, chemical structures, redox and optical properties afforded by both the CPE and POM families, our approach should enable the generation of a variety of well-defined, supramolecular architectures with enhanced functionality. Efficient charge injection and transport in organic electronic devices based on CPs is facilitated by a nanostructured, interpenetrating network at the active interface. Self-assembled CPE-POM networks may satisfy this requirement, whilst simultaneously offering enhanced functionality due to synergistic interactions between the two components.
The authors wish to thank Dr Padraic Nagle and Daniel Kehoe for help with preliminary experiments. This work is supported in part by SFI (Grant no. 12/IP/1608 and 08/IN.1/I2047).

\section{Notes and references}

1 Conjugated Polyelectrolytes. Fundamentals and Applications, ed. B. Liu and G. C. Bazan, Wiley-VCH, Weinheim, 2012.

2 T. Q. Nguyen, R. C. Kwong, M. E. Thompson and B. J. Schwartz, Appl. Phys. Lett., 2000, 76, 2454.

3 R. C. Evans, J. Mater. Chem. C, 2013, 1, 4190 and references therein. 4 (a) M. Knaapila, R. C. Evans, A. Gutacker, V. M. Garamus, M. Torkkeli, S. Adamczyk, M. Forster, U. Scherf and H. D. Burrows, Langmuir, 2010, 26, 5056; (b) A. Gutacker, N. Koenen, U. Scherf, S. Adamczyka, J. Pina, S. M. Fonseca, A. J. M. Valente, R. C. Evans, J. Seixas de Melo, H. D. Burrows and M. Knaapila, Polymer, 2010, 51, 1898.

5 (a) H. Jiang, X. Zhao and K. S. Schanze, Langmuir, 2006, 22, 5541; (b) H. D. Burrows, S. M. Fonseca, F. B. Dias, J. Seixas de Melo, A. P. Monkman, U. Scherf and S. Pradhan, Adv. Mater., 2009, 21, 1155; (c) J. Rubio-Magnieto, A. Thomas, S. Richeter, A. Mehdi, P. Dubois, R. Lazzaroni, S. Clément and M. Surin, Chem. Commun., 2013, 49, 5483; (d) S. M. Fonseca, R. P. Galvão, H. D. Burrows, A. Gutacker, U. Scherf and G. C. Bazan, Macromol. Rapid Commun., 2013, 34, 717; (e) R. C. Evans, M. Knaapila, N. Willis-Fox, M. Kraft, A. Terry, H. D. Burrows and U. Scherf, Langmuir, 2012, 28, 12348; $(f)$ M. E. H. Heeley, J. K. Gallaher, T. L. Nguyen, H. Y. Woo and J. M. Hodgkiss, Chem. Commun., 2013, 49, 4235.

6 (a) P. C. Marr, K. McBride and R. C. Evans, Chem. Commun., 2013, 49, 6155; (b) S. Neyshtadt, J. P. Jahnke, R. J. Messinger, A. Rawal, T. S. Peretz, D. Huppert, B. F. Chmelka and G. L. Frey, J. Am. Chem. Soc., 2011, 133, 10119; (c) R. C. Evans, A. G. Macedo, S. Pradhan, U. Scherf, L. D. Carlos and H. D. Burrows, Adv. Mater., 2010, 22, 3032; (d) S. Clément, A. Tizit, S. Desbief, A. Mehdi, J. D. Winter, P. Gerbaux, R. Lazzaroni and B. Boury, J. Mater. Chem., 2011, 21, 2733; (e) R. C. Evans and P. C. Marr, Chem. Commun., 2012, 48, 3742; $(f)$ T. Q. Nguyen, J.-J. Wu, B. J. Schwartz and S. H. Tolbert, Science, 2000, 288, 652; $(g)$ T.-Q. Nguyen, J. Wu, S. H. Tolbert and B. J. Schwartz, Adv. Mater., 2001, 13, 609.

7 (a) A. Proust, R. Thouvenot and P. Gouzerh, Chem. Commun., 2008, 1837; (b) J. M. Breen and W. Schmitt, Angew. Chem., Int. Ed., 2008, 47, 6904; (c) L. Zhang and W. Schmitt, J. Am. Chem. Soc., 2011, 133, 11240; (d) A. Dolbecq, E. Dumas, C. R. Mayer and P. Mialane, Chem. Rev., 2010, 110, 6009.

8 S. Liu and Z. Tang, Nano Today, 2010, 5, 267.

9 (a) D.-L. Long, E. Burkholder and L. Cronin, Chem. Soc. Rev., 2007, 36, 105; (b) M. Orlandi, R. Argazzi, A. Sartorel, M. Carraro, G. Scorrano, M. Bonchio and F. Scandola, Chem. Commun., 2010, 46, 3152; (c) J. J. Walsh, C. T. Mallon, A. M. Bond, T. E. Keyes and R. J. Forster, Chem. Commun., 2012, 48, 3593; (d) J. J. Walsh, J. Zhu, Q. Zeng, R. J. Forster and T. E. Keyes, Dalton Trans., 2012, 41, 9928.

10 (a) T. Liu, E. Diemann, H. L. Li, A. W. M. Dress and A. Müller, Nature, 2003, 426, 59; (b) G. J. T. Cooper and L. Cronin, J. Am. Chem. Soc., 2009, 131, 8368; (c) C. P. Pradeep, D.-L. Long and L. Cronin, Dalton Trans., 2010, 39, 9443.

11 (a) M. Lu, B. Xie, J. Kang, F.-C. Chen, Y. Yang and Z. Peng, Chem. Mater., 2005, 17, 402; (b) P. C. Yin, L. Jin, D. Li, P. Cheng, D. V. Vezenov, E. Bitterlich, X. Wu, Z. H. Peng and T. B. Liu, Chem.-Eur. J., 2012, 18, 6754; (c) S. Chakraborty, L. Jin, Y. Li, Y. Liu, T. Dutta, D.-M. Zhu, X. Yan, A. Keightley and Z. Peng, Eur. J. Inorg. Chem., 2013, 1799.

12 (a) P. Gómez-Romero and M. Lira-Cantú, Adv. Mater., 1997, 9, 144; (b) T. F. Otero, S. A. Cheng, D. Alonso and F. Huerta, J. Phys. Chem. B, 2000, 104, 10528.

13 (a) J. Canny, A. Teze, R. Thouvenot and G. Herve, Inorg. Chem., 1986, 25, 2114; (b) N. H. Nsouli, B. S. Bassil, M. H. Dickman, U. Kortz, B. Keita and L. Nadjo, Inorg. Chem., 2006, 45, 3858.

14 T. M. Swager, C. J. Gil and M. S. Wrighton, J. Phys. Chem., 1995, 99, 4886.

15 Charge balance is determined based on the number of charges per r.u. (+2), the average number of r.u., the number of charges on the POM $(-8)$ and the molar concentrations.

16 B. Grimm, C. Risko, J. D. Azoulay, J.-L. Brédas and G. C. Bazan, Chem. Sci., 2013, 4, 1807. 